\title{
T650/AFR-PE-4/FM680-1 Mode I Critical Energy Release Rate at High Temperatures: Experiments and Numerical Models
}

\author{
Peter A. Gustafson, Anthony M. Waas ${ }^{\dagger}$ \\ Department of Aerospace Engineering, University of Michigan, Ann Arbor, MI 48109, USA
}

\begin{abstract}
An experimental program to determine the mode $\mathbf{I}$ critical energy release rate $\left(G_{\text {Ic }}\right)$ of the T650/AFR-PE-4/FM680-1 material system is reported. Two forms of $G_{\text {Ic }}$ are determined over the range of 20 to $350{ }^{\circ} \mathrm{C}$, the area method critical energy release rate $G_{\mathrm{Ic}}^{\mathrm{a}}$ and the inverse method critical energy release rate $\left(G_{\mathrm{Ic}}^{\mathrm{i}}\right)$. The value of $G_{\mathrm{Ic}}$ was found to increase with increasing temperature. The inverse method is determined to be a very effective method of determining $G_{\text {Ic }}$ over the entire range of temperatures. Inverse modeling was completed using the finite element method, coupled with a novel Discrete Cohesive Zone Element, to determine $G_{\mathrm{Ic}}^{\mathrm{i}}$ over the range of crack advance in a given specimen. The element is described in detail, as well as the metrics used by the inverse algorithm. The FE models, subsequent to inverse modeling, accurately reproduce the experimental load-displacement curves. They therefore provide a capable analysis method, as well as a material system constitutive relation that contains a range of appropriate properties for use in the design and analysis of T650/AFR-PE-4/FM680-1 joints.
\end{abstract}

\section{Nomenclature}

$\begin{array}{ll}G_{\mathrm{I}} & \text { Energy release rate, } \mathrm{J} / \mathrm{m}^{2} \\ G_{\mathrm{Ic}} & \text { Critical energy release rate, } \mathrm{J} / \mathrm{m}^{2} \\ G_{\mathrm{Ic}}^{\mathrm{a}} & \text { Area method critical energy release rate, } \mathrm{J} / \mathrm{m}^{2} \\ G_{\mathrm{Ic}}^{\mathrm{i}} & \text { Inverse method critical energy release rate, } \mathrm{J} / \mathrm{m}^{2} \\ \sigma_{c} & \text { Cohesive strength of the adhesive system, } \mathrm{N} / \mathrm{m}^{2} \\ \sigma_{i}(\Delta u) & \text { Cohesive traction separation law of the adhesive system, } \mathrm{N} / \mathrm{m}^{2} \\ \bar{G}_{\mathrm{Ic}} & \text { Normalized critical energy release rate } \\ \bar{G}_{\mathrm{Ic}}^{\mathrm{a}} & \text { Normalized area method critical energy release rate } \\ \bar{G}_{\mathrm{Ic}}^{\mathrm{i}} & \text { Normalized inverse method critical energy release rate } \\ G_{\mathrm{Ic}}^{\mathrm{i} \text { ave }}(T=20) & \text { Average inverse method critical energy release rate at room temperature, } \mathrm{J} / \mathrm{m}^{2} \\ \bar{P} & \text { Normalized line load } \\ W_{\text {tot }} & \text { Total work done during displacement cycle, } \mathrm{J} \\ W_{\text {frac }} & \text { Work that creates fracture surfaces, J } \\ W_{\mathrm{pl}} & \text { Work that creates adherend permanent deformation, } \mathrm{J} \\ W_{\mathrm{dis}} & \text { Work that is dissipated by all other mechanisms, J } \\ W_{\text {ext }} & \text { External work during the displacement cycle, J } \\ w_{\text {tip }} & \text { DCB tip displacement, m } \\ b & \text { Specimen depth (out of plane), m } \\ h & \text { Specimen thickness, m } \\ l & \text { Specimen length, m } \\ a & \text { Apparent crack length measured from the hinge axis, } \mathrm{m} \\ & \end{array}$

*Graduate Student Research Assistant. Member AIAA. email: petegus@umich.edu

${ }^{\dagger}$ Professor. Associate Fellow, AIAA

Copyright (c) 2007 by Peter A. Gustafson. Published by the American Institute of Aeronautics and Astronautics, Inc. with permission. 


\begin{tabular}{|c|c|}
\hline$\Delta a$ & Apparent incremental crack advance, $\mathrm{m}$ \\
\hline$E I$ & Adherend Stiffness, $\mathrm{N} \mathrm{m}^{2}$ \\
\hline$U$ & Strain energy in DCB cantilever arms, J \\
\hline$M(x)$ & Moment in cantilever arm, $\mathrm{N} \cdot \mathrm{m}$ \\
\hline$K_{n m i}$ & Stiffness matrix component \\
\hline$K_{\mathrm{el}}$ & Element stiffness matrix \\
\hline$F_{n m i}$ & Element force component \\
\hline$F_{\mathrm{el}}$ & Element force vector \\
\hline$\Delta u_{n m i}$ & Relative displacement component \\
\hline$\Delta u_{i}^{\mathrm{IP}}(j)$ & Integration point relative displacement \\
\hline$u_{\mathrm{el}}$ & Element displacement vector \\
\hline$u_{n i}$ & Displacement component \\
\hline$A(j)$ & Cohesive area \\
\hline$\Delta t$ & FE solver time increment \\
\hline$N_{1}(j), N_{2}(j)$ & Element shape functions \\
\hline$\beta$ & Viscous zone weighting factor \\
\hline$\mu$ & Damping viscosity \\
\hline$\varphi$ & Area weighting factor \\
\hline$\zeta(j)$ & Element local coordinate \\
\hline$j$ & Integration point identifier \\
\hline$\sigma$ & Sample standard deviation of experimental quantities \\
\hline$R^{2}$ & Linear correlation coefficient of determination \\
\hline$x, y$ & Cartesian coordinates \\
\hline \multicolumn{2}{|l|}{ Subscripts } \\
\hline$i$ & The direction component of a vector \\
\hline$n$ or $n m$ & Acting on node $n$ or between nodes $n$ and $m$ \\
\hline \multicolumn{2}{|l|}{ Superscripts } \\
\hline IP & Integration point value \\
\hline$\mu$ & Viscous contribution \\
\hline$k$ & Traction separation law contribution \\
\hline
\end{tabular}

\section{Introduction}

High temperature resistant composite materials are currently being qualified for use as structural components of load bearing aeroshell systems. One candidate material system, T650/AFR-PE-4, has recently been the subject in an experimental program for material characterization. ${ }^{1}$ The AFR-PE4 resin, developed at the Air Force Research Lab, is a polyimide based matrix with a glass transition temperature of $360{ }^{\circ} \mathrm{C}$. It therefore has the potential for expanding the operating temperatures over which long fiber reinforced composite structures are used. Composite components based in AFR-PE4, as well as other similar resins, are targeted for use in aeroshell systems. They are expected to provide improved temperature resistance in the structural supports for ablative and resistive thermal protection systems, allowing a reduction in the mass of the protective layers.

It is critical that the T650/AFR-PE-4 material system be tested in a representative operating environment, therefore qualification and other tests must be completed over the operating temperature range of the material. This is true for all components of a material system, including the adhesive systems which will allow for efficient joining. In the present work, a composite material system composed of T650/AFR-PE-4 coupled with FM680-1 adhesive was assembled into double cantilever beam (DCB) specimens and tested to determine the critical energy release rate $G_{\mathrm{Ic}}$ as a function of temperature. Loading was applied at temperatures between $20-350{ }^{\circ} \mathrm{C}$.

In addition to qualification testing, computational modeling has become an indispensable tool in mission preparation. Numerical modeling of adhesive systems is an active area of research. Though finite element (FE) modeling of adhesively bonded joints began as as early as $1971,{ }^{2,3}$ the field is not yet mature. Recent efforts have largely focused on Continuous Cohesive Zone Models (CCZM) (including Kafkalidis and 
Thouless, ${ }^{4}$ Xie et al., ${ }^{5}$ Li et al. ${ }^{6,7}$ Valoroso and Champaney $^{8}$ ), the Virtual Crack Closure Technique (including Gillespie et al. ${ }^{9}$ Wang et al., ${ }^{10}$ Glaessgen et al., ${ }^{11}$ Krueger, ${ }^{12}$ Xie et al. ${ }^{13-15}$ ), and other adhesive region models (including Munoz et al., ${ }^{16}$ Goncalves et al., ${ }^{17}$ Goyal et al., ${ }^{18}$ Davies et al. ${ }^{19}$ ). The references provided here are not an exhaustive list.

The CCZM models are particularly well suited to composite materials, where the length scale associated with the process zone is larger than any characteristic length of the material. ${ }^{20-26}$ Cohesive zone models have begun to be incorporated into commercial software, including Abaqus ${ }^{\circledR},{ }^{27,28}$ as well as freely available research codes like Tahoe ${ }^{\circledR} .{ }^{29}$ However, despite their availability, the listed techniques can be challenging and expensive. Therefore, efforts are ongoing to develop improvements to the methods that are currently available.

An analysis technique called the Discrete Cohesive Zone Element (DCZM) was recently presented by Xie and Waas. ${ }^{30}$ Very similar in concept to non-linear spring-type elements, ${ }^{31,32}$ it is a promising alternative to the Continuous Cohesive Zone Elements. CCZM elements have been found to be mesh sensitive (in some circumstances), suffer from convergence difficulty during the softening portion of the cohesive law, and have sensitivity to aspect ratio. ${ }^{33-36}$ A rich description the strengths and weaknesses of the CZM methodologies is provided in Ref. (30). In contrast, the DCZM methodology treats the process zone as a pointwise spring foundation, discretized to node pairs of adjoining surfaces. The method is scalable to the node spacing, and is claimed to be free of mesh dependency. ${ }^{30}$ The stiffness matrix is sparse, and is therefore computationally efficient.

In this article, results are presented from an ongoing program that is intended to provide an experimentally validated model and analytical tool for joint design with a T650/AFR-PE-4/FM680-1 material system. Experiments and analysis of the Mode I critical energy release rate $\left(G_{\text {Ic }}\right)$ are presented in two forms. First, the area method critical energy release rate $\left(G_{\mathrm{Ic}}^{\mathrm{a}}\right)$ is presented, determined by image analysis of crack propagation. Second, the inverse method critical energy release rate $\left(G_{\mathrm{Ic}}^{\mathrm{i}}\right)$ is presented, computed through the use of inverse FE analysis based on the DCZM methodology. Using these tools, a set of constitutive relations is developed which effectively model T650/AFR-PE-4/FM680-1 Mode I joint behavior over the temperature range $20-350{ }^{\circ} \mathrm{C}$.

NOTE: Due to ITAR restrictions on the subject materials, some detail is excluded from this article. The derived material properties are presented as normalized quantities. Some other properties and manufacturing details are omitted. All numerical values and plots are normalized by the mean of the inverse method critical energy release rate, computed from room temperature tests $\left(G_{\mathrm{Ic}}^{\mathrm{i} \text { ave }}(T=20)\right)$.

$$
\begin{aligned}
\bar{G}_{\mathrm{Ic}}^{\mathrm{a}} & =\frac{G_{\mathrm{Ic}}^{\mathrm{a}}}{G_{\mathrm{Ic}}^{\mathrm{i} a v e}(T=20)}, \\
\bar{G}_{\mathrm{Ic}}^{\mathrm{i}} & =\frac{G_{\mathrm{Ic}}^{\mathrm{i}}}{G_{\mathrm{Ic}}^{\mathrm{i} \text { ave }}(T=20)}, \\
\bar{P} & =\frac{P}{G_{\mathrm{Ic}}^{\mathrm{i} \text { ave }}(T=20)},
\end{aligned}
$$

\section{Experimental Determination of Mode I Joint Performance}

The foundation for any validated model is a database of experimental observations that can be used for material characterization and model comparison. In the following section, an experimental program is presented for determining the mode I critical energy release rate of the T650/AFR-PE-4/FM680-1 adhesive material system over a broad range of temperatures.

\section{A. Specimen Preparation}

DCB specimens were prepared in batches using bidirectional woven T650 lamina, preimpregnated with AFRPE-4 by Cytec Corporation. The layers are arranged by hand layup into $[0,90]_{s}$ laminates, and cured in a Wabash model 30-1515 hot press. The multi-step curing cycle followed the manufacturer's recommendation ${ }^{1}$ as closely as possible, with modifications required for hot press operations. ${ }^{a}$ The cured laminate plate had two distinct surface textures, referred to as smooth (released from the stainless steel mold plate) and

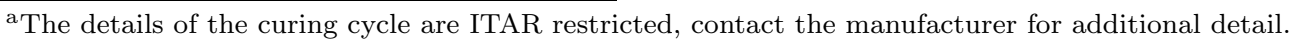


rough (released from the the peel ply/fiberglass batting). The cured plate geometry was approximately $315 \times 315 \times 1.25 \mathrm{~mm}$.

Following the cure cycle, each laminate was cut into four smaller plates of approximately $155 \times 155 \mathrm{~mm}$. All specimens were prepared with adherends coming from the same laminate. Prior to any bonding, these laminates were lightly roughened with 200 grit sandpaper and cleaned with acetone. The laminates, in pairs, were bonded together using Cytec FM680-1 adhesive film (carried on

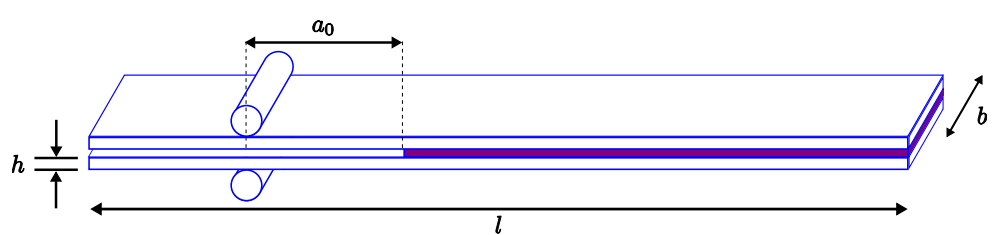

Figure 1: Nominal specimen layout. a fiberglass scrim), which was also cured in the hot press. ${ }^{\mathrm{b}}$ The laminates were arranged so that the adhesive layer was in contact with one rough and one smooth side of the adherends. A $50 \mu \mathrm{m}$ film sheet of Kapton (coated with Loctite 770-NC mold release) was inserted between the adherends to initiate a crack.

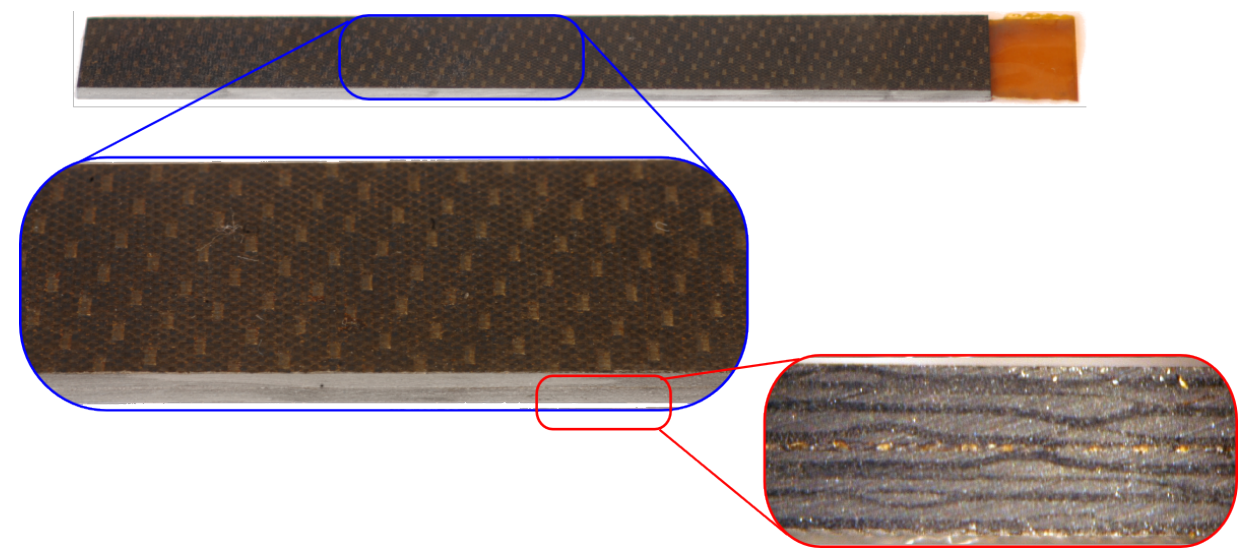

Figure 2: T650/AFR-PE-4/FM680-1 DCB specimen shown at different scales

Subsequent to the adhesive curing cycle, the assembly was post-cured according to the manufacturer's recommended cycle. The edges of the bonded plates were trimmed, and individual specimens were cut from the remaining material. The nominal geometry of the prepared specimen is shown in figure 1 , and figure 2 shows a typical specimen at several visual scales. The nominal length $(l)$ was $130 \pm 3 \mathrm{~mm}$, the nominal width $(b)$ was $20 \pm 0.3 \mathrm{~mm}$, and the nominal thickness of one adherend $(h)$ was $1.25 \pm 0.05 \mathrm{~mm}$. The position of the Kapton was $20 \pm 2 \mathrm{~mm}$ relative to the hinge. Due to the high temperatures to which the joints were subjected, the hinges were attached with \#4-40 bolts. Holes were drilled in the specimens, on the opposite side of the cantilever arm, to accommodate these bolts. The hole size was set so that the conical heads of the bolts were approximately flush with the inside surfaces of the DCB specimen (the bolt shank protruded outward from the specimen centerline). The resulting hinged specimen had less than $0.5 \mathrm{~mm}$ of initial displacement caused by the bolt heads.

\section{B. Experimental Protocol}

The experiments were completed on an Instron model 5585 electro-mechanical loading frame. The specimens, including grips, were enclosed in an Instron model 3119 environmental chamber and brought to the specified temperatures $\left(T=[20,150,250,350]{ }^{\circ} \mathrm{C}\right)$. Four specimens were tested at each temperature level. The air inside the environmental chamber was constantly stirred to ensure uniformity, and was maintained to $\pm 2{ }^{\circ} \mathrm{C}$. The chamber was allowed a minimum of 20 minutes to obtain thermodynamic equilibrium after reaching the specified temperature. Prior to the measured load-displacement cycle, the setup was

\footnotetext{
${ }^{\mathrm{b}}$ The adhesive cure cycle was also modified slightly from the manufacturer's recommendation due to hot press operations.
} 
confirmed and a natural crack was initiated by enforcing a crosshead displacement of $5 \mathrm{~mm}$ while at temperature. Therefore, the initial crack length $\left(a_{0}\right)$ prior to testing was determined by this initial enforced displacement. The DCB specimens were subsequently loaded via displacement control at $5 \mathrm{~mm}$ per minute. An escalating sawtoothed displacement pattern was prescribed, where the bounding displacements were: $w_{\text {tip }}=[0,8,0,11,0,14,0,17,0,20] \mathrm{mm}$. Load and displacement measurements were taken at a minimum of $10 \mathrm{~Hz}$. Photographic images were taken at a minimum of 5 second intervals, in order to determine the apparent crack position.

\section{Analysis Of The Experimental Results}

\section{A. Representative Test Results and $G_{\mathrm{Ic}}^{\mathrm{a}}$}
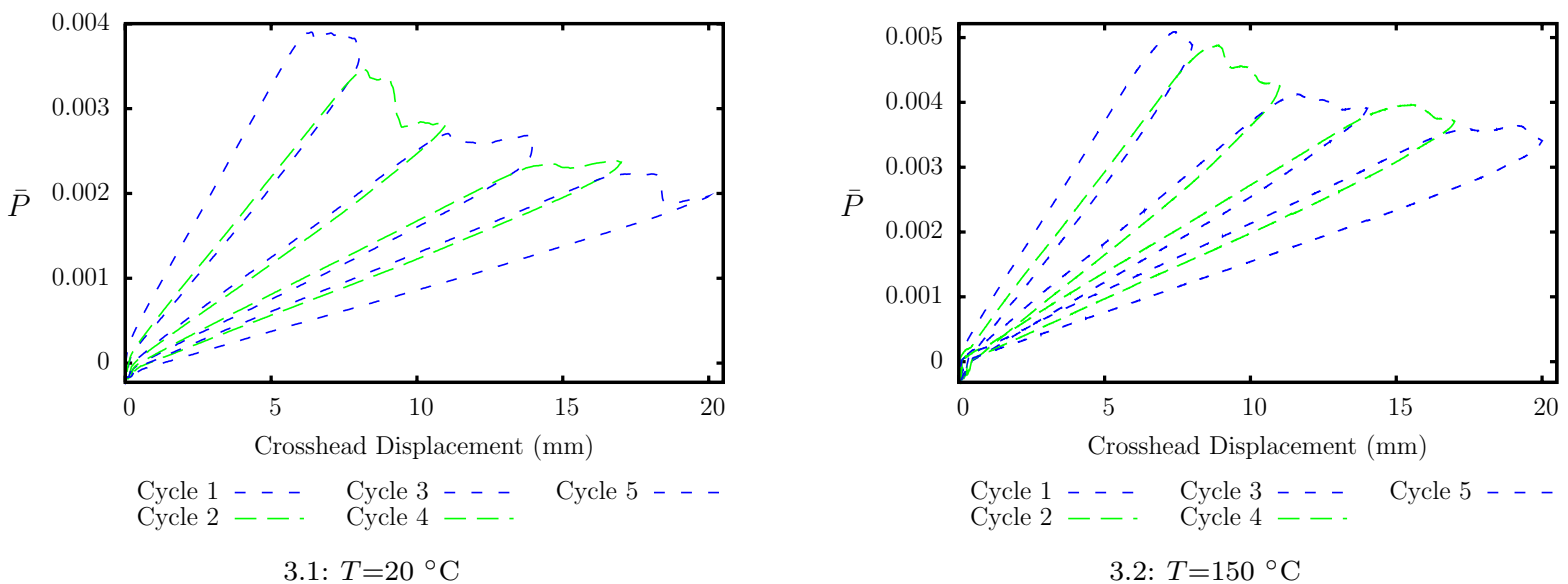

3.2: $T=150^{\circ} \mathrm{C}$
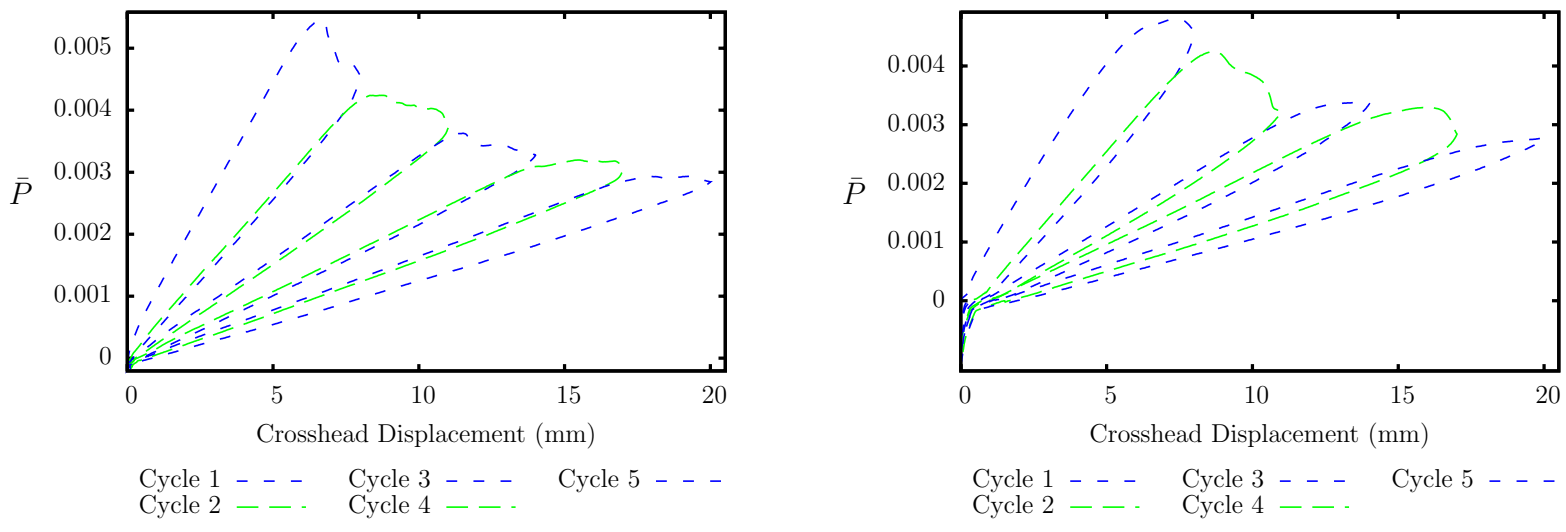

3.3: $T=250{ }^{\circ} \mathrm{C}$

Cycle 1 - - - Cycle 3 - - Cycle 5 - Cycle 2 - - Cycle $4-\ldots$

3.4: $T=350{ }^{\circ} \mathrm{C}$

Figure 3: Typical normalized load-displacement curves for T650/AFR-PE-4/FM680-1 DCB specimens.

A set of typical load-displacement curves are shown in figure 3. The curves were numerically integrated to determine the total work done during each displacement cycle. The total work is composed of several components:

$$
W_{\text {tot }}=W_{\text {frac }}+W_{\mathrm{pl}}+W_{\mathrm{dis}},
$$

where $W_{\text {tot }}$ is the total work done, $W_{\text {frac }}$ is the work done to create new fracture surfaces, $W_{\mathrm{pl}}$ is the work that causes permanent deformation (hereafter referred to as plasticity) in the adherends, and $W_{\text {dis }}$ are all other dissipative mechanisms. For a linear-elastic DCB specimen, the plastic and dissipative terms are absent in Eq. (2), and all the external work during a cycle goes to the creation of fracture surfaces. The critical 
energy release rate $\left(G_{\mathrm{Ic}}\right)$ is equal to this fracture work divided by the new crack surface area:

$$
G_{\mathrm{Ic}}=\frac{W_{\mathrm{frac}}}{\Delta a \cdot b} .
$$

It was observed that Eq. (3) is a good approximation for the T650/AFR-PE-4/FM680-1 specimens at room temperature. After the test, there was no visual indication of plastic deformation in the specimen. As shown in figure 3.1, the sawtooth loading pattern exhibits linear initial loading and linear unload-reload cycles with minimal hysteresis. The specimen load goes to the zero load point as displacement goes to zero, indicating little or no permanent deformation. However, Eq. (3) does not hold at $350{ }^{\circ} \mathrm{C}$ due to moderate permanent deformation. This can also be seen in figure 3.4, where the sawtooth displacement cycle exhibits significant differences between the unload and reload load-displacement curves. This hysteresis is indicative of other dissipative mechanisms playing a non-negligible role in the test. The unload path does not return to zero load at zero displacement, which re-enforces the observation of plastic deformation. Further, in two of the four specimens tested at $350{ }^{\circ} \mathrm{C}$, the specimen failed due to adherend fracture, with high amounts of dissipated energy associated with the fracture. In Ref. (1), the T650/AFR-PE-4 material system was found to suffer a significant reduction in the interlaminar shear strength, therefore the two specimen failures at this temperature are not surprising.

Due to the uncertain non-linear and dissipative effects, the area method critical energy release rate is defined as:

$$
G_{\mathrm{Ic}}^{\mathrm{a}}=\frac{W_{\mathrm{tot}}}{\Delta a \cdot b} .
$$

Care must be exercised that the area method critical energy release rate, $G_{\text {Ic }}^{\mathrm{a}}$, is not confused with the "true" critical energy release rate at high temperature. At present, the authors lack sufficient information to completely determine the temperature dependence and contributions of plastic work $\left(W_{\mathrm{pl}}\right)$ and other dissipative mechanisms $\left(W_{\text {dis }}\right)$ to the total work $\left(W_{\text {tot }}\right)$ in the DCB test, therefore $G_{\text {Ic }}^{\text {a }}$ cannot be considered a "true" $G_{\text {Ic }}$. An alternative method for determining $G_{\text {Ic }}$ will be presented in section IV.

\section{Determining the Apparent Crack Advance}

Image analysis was used to determine the time history of the apparent crack position. A label-paper grid with $0.5 \mathrm{~mm}$ spacing was adhered to the edge of each specimen, and used to aid in determining the crack position in post-processing. For each specimen, a pixel length calibration was done. A typical photograph had 50 pixels $/ \mathrm{mm}$. The initial crack position was measured from a line connecting the center of the hinges to the initial crack tip. In subsequent images, common points were identified and used to determine the prior crack position. Crack propagation was measured from the prior crack position to the current crack position in each frame. In this way, the apparent crack position $(a)$ and apparent crack increment $(\Delta a)$ could be determined even when the global deflection would make direct linear measurement from the hinge difficult. At a minimum, image analysis was carried out at the beginning and end of the cycle as well as the beginning

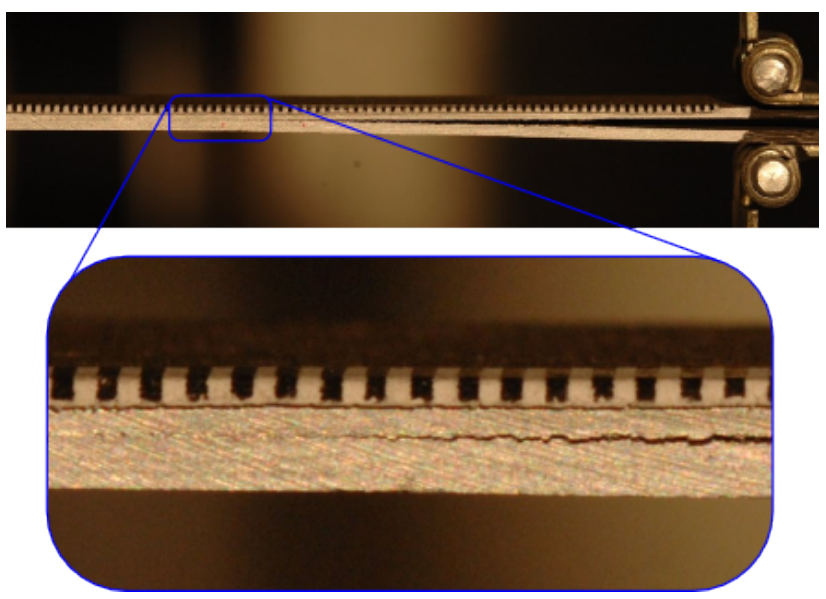

Figure 4: Typical image used for analysis of apparent crack propagation. of each unload phase of the cycle. Therefore, all subcycle crack positions were determined, as well as the initial and final crack positions. Additional images were analyzed, as required, to track crack position throughout each test.

By using the area method to determine the time history of $a$, the area method critical energy release rate $G_{\mathrm{Ic}}^{\mathrm{a}}$ was calculated with Eq. (4) for each specimen. The average and standard deviation $(\sigma)^{\mathrm{c}}$ of the

${ }^{\mathrm{c}}$ The reported standard deviations in this work are sample standard deviations, the square-root of the unbiased estimator for the variance. 


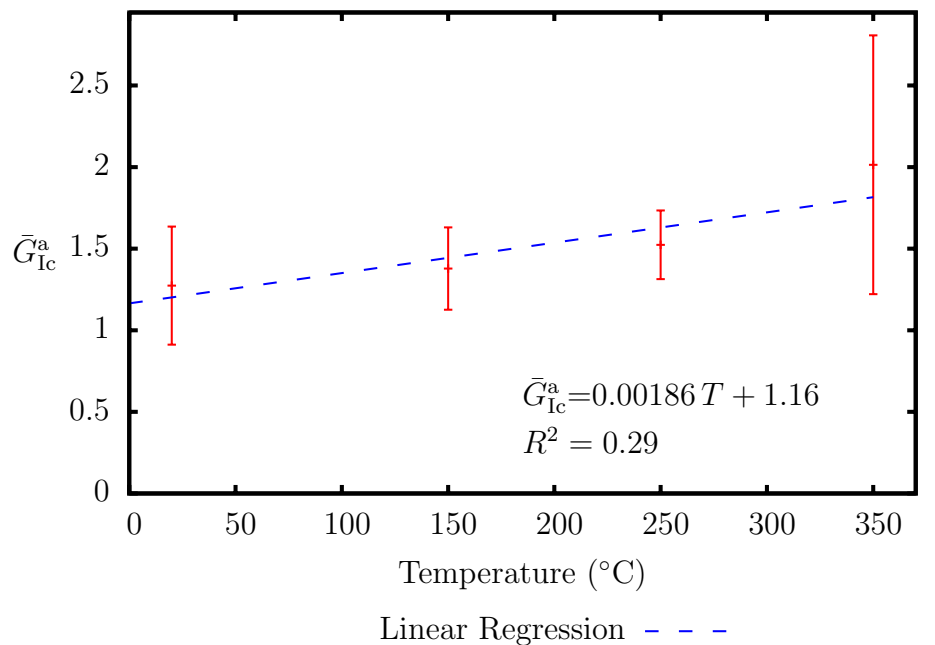

Figure 5: Area method critical energy release rate $G_{\text {Ic }}^{\text {a }}$ as a function of temperature. The error bars represent $\bar{G}_{\mathrm{Ic}}^{\mathrm{a}} \pm \sigma$.

four specimens were calculated for each temperature, and are shown in figure 5 as well as table 2. A loose positive correlation was found between the temperature and $G_{\mathrm{Ic}}^{\mathrm{a}}{ }^{\mathrm{d}}$. This increase in $G_{\mathrm{Ic}}^{\mathrm{a}}$ is consistent with an increase in material ductility at higher temperatures. However, at this time there is insufficient information to eliminate the possible influence of a gradual increase in adherend plasticity with temperature. Permanent deformation is readily apparent in the specimens tested at $350{ }^{\circ} \mathrm{C}$.

\section{B. Additional Observations}

The area method described above has been determined to be less reliable than the various compliance calibration methods (CCM). ${ }^{37}$ Due to the nature of the calibration, CCM methods require consistent adherend stiffnesses from specimen to specimen. With thin adherends consisting of only a few layers, such as were used in the present experimental study, adherend stiffness may not be consistent from specimen to specimen. Small variations in thickness and small differences in fiber position within the cross section inevitably lead to differences in stiffness, since there is little opportunity for strain averaging in thin laminates. This stiffness uncertainty is further emphasized by the manufacturing variations inherent in the laminate hand layup process. In the present study, the standard deviation on the measured adherend stiffness was $7.4 \%$ of the mean stiffness, as determined by 3-point bend tests at room temperature. Additionally, since compliance is a function of temperature over the temperature range of interest, the calibration of compliance becomes difficult due to the number of specimens required and the tedious nature of the calibration. Therefore, the non-calibration area and inverse methods (described in section IV) are used in this work.

In addition to the adherend fracture at $350{ }^{\circ} \mathrm{C}$ noted above, it was also observed that the principle adhesive failure was always at the interface with the rough side of the adherend. In each case, the fiberglass scrim carrier remained bonded to the smooth adherend. In a few specimens, small patches of scrim $\left(\sim 30 \mathrm{~mm}^{2}\right)$ were found on the rough adherend, however this was uncommon. It is therefore very likely that the surface roughness played a significant role in the adhesive failure.

Finally, it was observed that the critical energy release rates $\left(G_{\text {Ic }}^{\mathrm{a}}\right.$ and $\left.G_{\text {Ic }}^{\mathrm{i}}\right)$, as well as the peak loads themselves, increased with increasing temperature. This trend has been observed in other work, where it has been found that the material ductility increases with increasing temperature. ${ }^{37,38}$ However, the observed trend is important, since $\mathrm{Asp}^{38}$ concluded that the literature is ambiguous as to the effects of temperature on $G_{\text {Ic }}$.

\footnotetext{
${ }^{\mathrm{d}}$ The mean and standard deviation at $350{ }^{\circ} \mathrm{C}$ in figure 5 is based on the two specimens which did not exhibit adherend fracture.

eAsp's conclusion was with respect to interlaminar $G_{\text {Ic }}$, however the result is likely general.
} 


\section{Inverse FE Modeling to Determine $G_{\mathrm{Ic}}^{\mathrm{i}}$}

\section{A. Description of the FE Model}

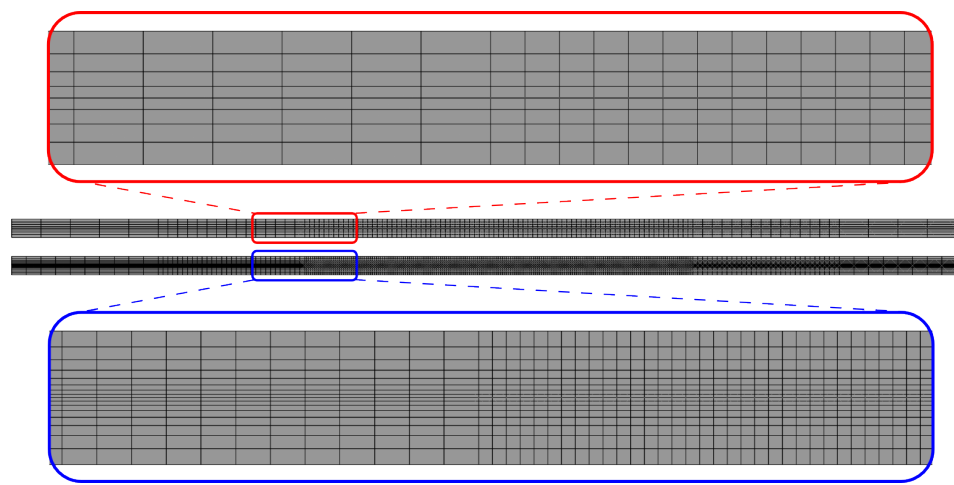

6.1: The small (top) and large (bottom) meshes used to evaluate convergence.

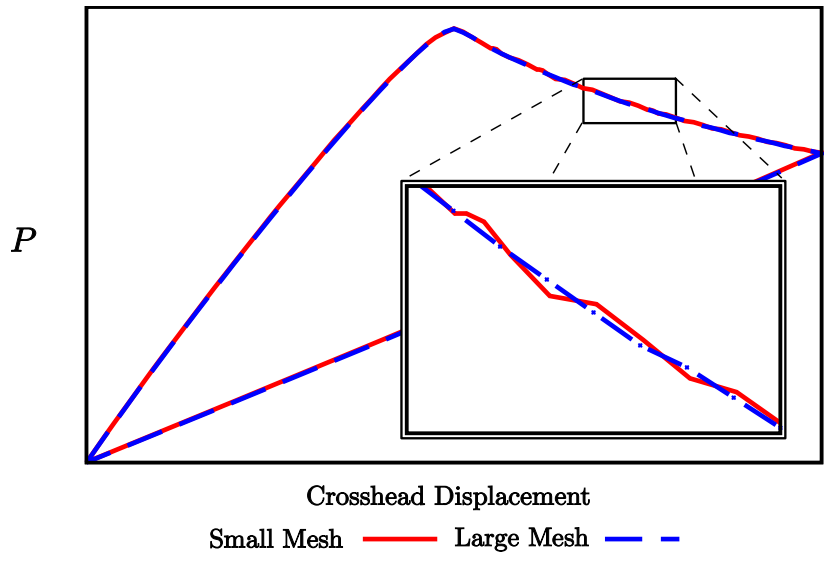

6.2: Predicted load-displacement results for the small and large meshes. The small mesh exhibits "chatter" that is not present in the large mesh.

Figure 6: DCZM based FE models in two different mesh densities

The intent of this work is to provide a verified material constitutive model and proven modeling capability of the T650/AFR-PE-4/FM680-1 material system in adhesive joints. Therefore, the experimental results of the prior section are used to generate a FE model of the DCB test. The FE model was used for quantitative inverse modeling of the critical energy release rate from the experiments.

A $2 \mathrm{D}$ model was created and Abaqus ${ }^{\circledR 27}$ was

Table 1: Properties of the FE mesh (Approximate)

\begin{tabular}{l|c|c}
\hline \hline & Small Mesh & Large Mesh \\
\hline Elements & 1050 & 4700 \\
Nodes & 1200 & 5000 \\
Solution time (s) & 25 & 145 \\
\hline \hline
\end{tabular}

used as the FE solver. The adherends were modeled with linear elastic, orthotropic CPE4I elements, and the adhesive was replaced by a layer of novel Discrete Cohesive Zone Model (DCZM) Elements, described in detail in subsection B. Two meshes, shown in figure 6 and detailed in table 1, were used and were found to provide nearly identical results (in terms of predicted load-displacement curve) as shown in figure 6.2. This reinforces the claim made in Ref. (30) that the DCZM element is essentially mesh independent. However, the authors' observed that the model's ability to obtain a converged solution is mesh dependent. Due to the small CPU time requirements of the model, a dense mesh was chosen for additional study, since it exhibited slightly less "chatter" during steady state crack propagation. It was therefore deemed to be more likely to 
converge for all model inputs.

\section{B. Description of the Discrete Cohesive Zone Element}

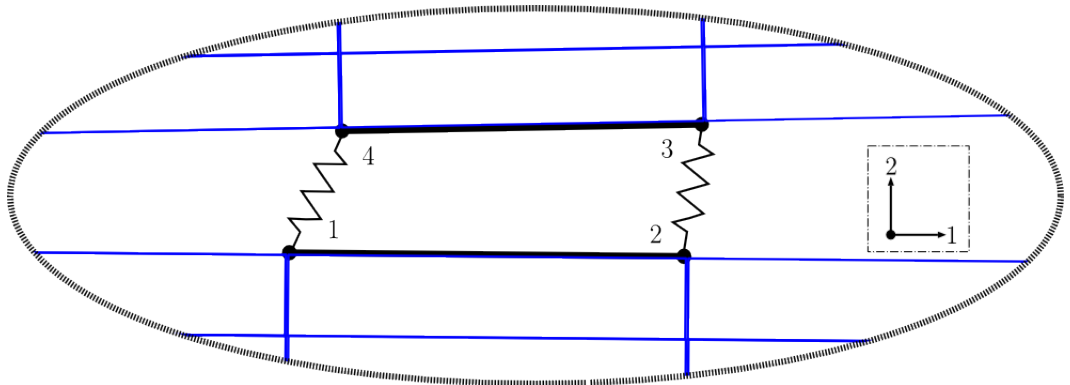

7.1: Four-node DCZM element with surrounding elements. Adhesion is enforced with non-linear springs between node pairs.

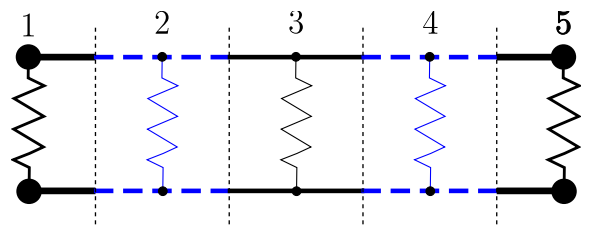

7.2: Example of DCZM element with 5-point integration. The spacing is uniform, and the contact is uniformly distributed with the exception of the nodal integration points. The nodal integration points are allotted $1 / 2$ the contact area associated with the internal integration points.

The core of the FE model described above is the Discrete Cohesive Zone Model (DCZM) element. The DCZM element in this work (hereafter referred to as "the current element") is derived from the formulation of Xie and Waas ${ }^{30}$ (hereafter referred to as "the Xie element"). However, the formulation has been modified to provide a (perceived) improvement in user interface and the addition of user controlled damping.

\section{The Element Layout}

The first modification in the current element is to the node layout. The node numbering and connectivity in the Xie element does not follow common convention. It is a four-node element with two "dummy" nodes (therefore, the element transmits forces only at two nodes). The dummy nodes serve to measure the adhesive area that the element represents. Although the nodal layout of the Xie element is fully capable of providing the intended function of the element, it is recognized that a more standard node layout is usually desired, provided that no sacrifice in function is required. Therefore, the node connectivity in the current element, shown in figure 7.1, conforms to the layout for a $2 \mathrm{D}$ four-node element in Abaqus ${ }^{\circledR}$. There are no dummy nodes, the contact area is measured from nodes that are active, and all nodes transfer adhesive forces.

Although the current node arrangement has the advantage of providing a more conventional node layout, it requires a slight increase in per contact node computation load over that of the Xie node arrangement. This is a consequence of (most) active nodes being active in two elements, requiring additional cost due to the evaluation of stiffness and force at each active node in an element. However, unlike the Xie element, the current element is formulated so that an arbitrary number of integration points can be inserted between the nodes on the contact surfaces. Therefore, the current element has the potential to be a "softer" element, smoothing transitions in highly non-linear traction separation laws. Additional integration points offer the possibility of improved convergence ${ }^{19}$ in marginally stable analysis at a given mesh density, or the use of lower mesh densities. ${ }^{f}$

\footnotetext{
${ }^{f}$ The authors have experienced circumstances where an increase in the number of integration points in a DCZM element has allowed a DCB mesh to obtain a converged solution that would otherwise fail to do so. However, this aspect of the element formulation is not explored in this work. No claim is made regarding the robustness of this strategy as a method to improve
} 


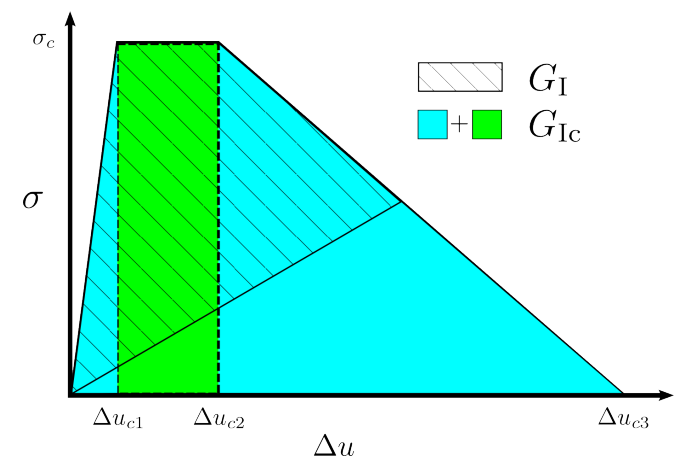

Figure 7: The traction separation law implemented in the current DCZM element. This figure represents either the Mode I or the Mode II law, though in general the laws are not the same shape.

The current element uses a trapezoidal traction separation law, schematically shown in figure 7. This is modified from the triangular law used in the Xie element. In the DCZM element, the critical energy release rate is the area under the curve. It has been shown that the form of the traction separation law is not critical, ${ }^{30}$ however the trapezoidal formulation offers somewhat more flexibility for controlling the size of the process zone than does a triangular law. In the current element, the "plastic" fraction (the rectangular area in between $\Delta u_{c 1}$ and $\Delta u_{c 2}$ in figure 7 ) of the critical energy release rate is a user controllable variable. It is bound by zero (restoring a triangular law) and one.

Although the current element is a four-node element, in practice it is simply an element consisting of four two-node non-linear spring elements and four two-node linear dashpot elements. These sub-elements transmit spring forces in the $x$ (shear) and $y$ (peel) directions for each of two node pairs. Therefore, the element force vector and stiffness matrix shown in Eq. (5) appear as they would if four spring elements were assembled.

$$
K_{\mathrm{el}}=\left[\begin{array}{cccccccc}
K_{14 x} & 0 & 0 & 0 & 0 & 0 & -K_{14 x} & 0 \\
0 & K_{14 y} & 0 & 0 & 0 & 0 & 0 & -K_{14 y} \\
0 & 0 & K_{23 x} & 0 & -K_{23 x} & 0 & 0 & 0 \\
0 & 0 & 0 & K_{23 y} & 0 & -K_{23 y} & 0 & 0 \\
0 & 0 & -K_{23 x} & 0 & K_{23 x} & 0 & 0 & 0 \\
0 & 0 & 0 & -K_{23 y} & 0 & K_{23 y} & 0 & 0 \\
-K_{14 x} & 0 & 0 & 0 & 0 & 0 & K_{14 x} & 0 \\
0 & -K_{14 y} & 0 & 0 & 0 & 0 & 0 & K_{14 y}
\end{array}\right], F_{\mathrm{el}}=\left[\begin{array}{c}
-F_{14 x} \\
-F_{14 y} \\
-F_{23 x} \\
-F_{23 y} \\
F_{23 x} \\
F_{23 y} \\
F_{14 x} \\
F_{14 y}
\end{array}\right]
$$

A detailed derivation of the components of Eq. (5) is deferred to subsection C below.

\section{The Internal Damping}

The second major modification to the Xie element is the addition of internal damping. In Ref. (30) it was reported that the Xie element had no convergence difficulties associated with a triangular traction separation law. In the present work, it was observed that the local stability of a DCB test may depend on the traction separation behavior of the constituents and the strain energy present in the specimen. The crack advance was observed to be discontinuous on occasion, advancing in small increments. Though the DCB exhibited a globally stability, the local instabilities in this work require additional investigation. ${ }^{\mathrm{g}}$ This trait is mirrored in the FE model, and in addition the ability of the solver to obtain a converged solution may also depend on the mesh density.

In physical tests, it is not uncommon for this stepwise (stick-slip) dynamic crack propagation to occur. Further, it is impossible to construct a cohesive element that is unconditionally convergent for an implicit

convergence or reduce CPU cost in a DCB or other analysis, only that the potential exists to do so.

${ }^{\mathrm{g}}$ The local stick-slip effects are to be addressed in an intended journal submission. ${ }^{39}$ 
static solver, since crack propagation stability is dependent on the energetics of the system. Ideally, all forms of dynamic crack advance (including stepwise dynamic) would be addressed with a dynamic element formulation and a dynamic FE solver (implicit or explicit). However, there are many cases where an implicit solver is preferred and appropriate, therefore it is not uncommon to add dissipative mechanisms to the static formulation in order to stabilize the solution and facilitate convergence. This capability is built into many solvers. In Abaqus ${ }^{\circledR}$, for example, a cohesive analysis could include dissipation at every degree of freedom ${ }^{\mathrm{h}}$ or locally at the cohesive section ${ }^{\mathrm{i}}$. If the dynamic cracking occurs in small stepwise increments and a dynamic analysis is not desired, it is justifiable to add small amounts of dissipation to the implicit static solution. The global solution variables (stiffness, load) only requires small changes, and the dissipation could be considered to represent the energy that goes into sound, heat, or other viscous damping effects. Comparison between the FE model and the experimental data is enough to determine if this modeling technique is justified. Caution must be used, however, since different geometries will exhibit different stability boundaries.

In light of the above, a user controlled option of adding viscous dissipation was formulated into the current DCZM element. This is accomplished the addition of linear dashpots on each node pair in each direction.

\section{DCZM Force Vector and Stiffness Matrix}

The element load vector and stiffness matrix components presented in Eq. (5) are derived here in detail. The displacement vector for the current element is given by:

$$
u_{\mathrm{el}}=\left[\begin{array}{llllllll}
u_{1 x} & u_{1 y} & u_{2 x} & u_{2 y} & u_{3 x} & u_{3 y} & u_{4 x} & u_{4 y}
\end{array}\right]^{T} .
$$

Each component of the reaction force $F_{n m i}$ (acting between nodes $n$ and $m$, direction $i$ ) and stiffness matrix $K_{n m i}$ is composed of the combination of traction separation law (superscript $k$ ) and viscous (superscript $\mu$ ) components:

$$
\begin{aligned}
F_{14 i} & =F_{14 i}^{k}+F_{14 i}^{\mu}, \\
F_{23 i} & =F_{23 i}^{k}+F_{23 i}^{\mu}, \\
K_{14 i} & =K_{14 i}^{k}+K_{14 i}^{\mu}, \\
K_{23 i} & =K_{23 i}^{k}+K_{23 i}^{\mu} .
\end{aligned}
$$

\section{Traction Separation Law Contributions to the Element Matrices}

The traction separation law component of the force vector is a moment balanced sum of integration point forces over an arbitrary number of equally spaced integration points $\left(n_{\mathrm{IP}}\right)$ :

$$
\begin{aligned}
F_{14 i}^{k} & =\sum_{j=1}^{n_{\mathrm{IP}}} N_{1}(j) \cdot F_{i}^{k \mathrm{IP}}(j), \\
F_{23 i}^{k} & =\sum_{j=1}^{n_{\mathrm{IP}}} N_{2}(j) \cdot F_{i}^{k \operatorname{IP}}(j) .
\end{aligned}
$$

In Eq. (8), the integration point forces $F_{i}^{k \operatorname{IP}}(j)$ are weighted by shape functions, in order to transfer the moment produced by the integration point forces to the nodal forces:

$$
\begin{aligned}
& N_{1}(j)=\left(\frac{1-\zeta(j)}{2}\right), \\
& N_{2}(j)=\left(\frac{1+\zeta(j)}{2}\right) .
\end{aligned}
$$

\footnotetext{
${ }^{\mathrm{h}}$ Via the ( $\left.{ }^{*} S T A T I C, S T A B I L I Z E\right)$ keyword

${ }^{\mathrm{i}}$ Via the ( ${ }^{*}$ SECTION CONTROLS, VISCOSITY $\left.=\mu\right)$ keyword
} 
The local coordinate $\zeta(j)$ for integration point number $\left(j=\left[1, \ldots, n_{\mathrm{IP}}\right]\right)$ varies linearly from -1 to 1 at the left and right edges of the element respectively:

$$
\zeta(j)=\left(\frac{2}{n_{\mathrm{IP}}-1}\right) \cdot(j-1)-1 .
$$

The integration point forces are:

$$
F_{i}^{k \mathrm{IP}}(j)=\sigma_{i}\left(\Delta u_{i}^{\mathrm{IP}}(j)\right) \cdot A^{\mathrm{IP}}(j),
$$

where the traction separation law is given by $\sigma_{i}\left(\Delta u_{i}^{\mathrm{IP}}(j)\right)$, and $A^{\mathrm{IP}}(j)$ is the area associated with the integration point. In principle, the law is arbitrary, however a trapezoidal law has been implemented, as shown in figure 7. The integration point relative displacement is determined by a linear interpolation of the nodal DOF relative displacement:

$$
\Delta u_{i}^{\mathrm{IP}}(j)=N_{1}(j) \cdot \Delta u_{14 i}+N_{2}(j) \cdot \Delta u_{23 i} .
$$

The node pair relative displacements are:

$$
\begin{aligned}
& \Delta u_{14 i}=u_{4 i}-u_{1 i}, \\
& \Delta u_{23 i}=u_{3 i}-u_{2 i},
\end{aligned}
$$

and the areas associated with the integration points are:

$$
A^{\mathrm{IP}}(j)=\frac{b \cdot\left(x_{2}-x_{1}\right)}{\varphi\left(n_{\mathrm{IP}}-1\right)} .
$$

In Eq. (14), the elemental contact area is distributed to the integration points. Essentially, it is divided into $\left(n_{\mathrm{IP}}-1\right)$ parcels. All integration points have the same area, except for the nodal integration points which divide the final parcel into two parts. This parcelling is accomplished by the term $(\varphi)$ in the denominator of Eq. (14):

$$
\varphi=\left\{\begin{array}{lll}
2 & \text { if } & j=\left\{1, n_{\mathrm{IP}}\right\} \\
1 & \text { if } & j \neq\left\{1, n_{\mathrm{IP}}\right\}
\end{array}\right.
$$

The integration point positions include the nodes positions, therefore a minimum of two integration points are required. Figure 7.2 provides an example of the integration point layout and area weighting for $n_{\mathrm{IP}}=5$.

With the force vector derivation complete, the traction law stiffness components are derived in a very similar way. The integration point stiffness is:

$$
K_{i}^{k \mathrm{IP}}(j)=\frac{d}{d \Delta u_{i}^{\mathrm{IP}}(j)} \sigma_{i}\left(\Delta u_{i}^{\mathrm{IP}}(j)\right) \cdot A^{\mathrm{IP}}(j),
$$

and the element stiffness matrix components are:

$$
\begin{aligned}
K_{14 i}^{k} & =\sum_{j=1}^{n_{\mathrm{IP}}} N_{1}(j) \cdot K_{i}^{k \mathrm{IP}}(j), \\
K_{23 i}^{k} & =\sum_{j=1}^{n_{\mathrm{IP}}} N_{2}(j) \cdot K_{i}^{k \mathrm{IP}}(j) .
\end{aligned}
$$

The derivative in Eq. (16) is discontinuous at the critical displacements (for the trapezoidal traction separation law), therefore it is applied in a discrete $\left(\Delta u \leq \Delta u_{c}\right)$ sense.

\section{Dissipative Contributions to the Element Matrices}

Having completed the derivation for the traction separation law contributions to the elemental matrices, it was reported in subsection B that a method of energy dissipation is required (for some geometries and traction separation laws) to facilitate a converged solution. In the current element, dissipation is implemented 
in the form of an internal dashpot on each relative degree of freedom. The dashpot components of the force are given by:

$$
\begin{aligned}
& F_{14 i}^{\mu}=\mu_{14 i} \cdot \Delta \dot{u}_{14 i} \\
& F_{23 i}^{\mu}=\mu_{23 i} \cdot \Delta \dot{u}_{23 i}
\end{aligned}
$$

where the viscosities $\left(\mu_{14 i}, \mu_{23 i}\right)$ are non-zero only in a viscous zone defined by a user specified multiplier $(\beta>1)$ of the critical relative displacement $\Delta u_{c 3 i}$ :

$$
\mu_{n m i}=\left\{\begin{array}{lll}
\mu_{i} & \text { if } & \delta_{i} \leq \beta \Delta u_{c 3 i}, \\
0 & \text { if } & \delta_{i}>\beta \Delta u_{c 3 i} .
\end{array}\right.
$$

In the authors' experience, $\beta$ values between 3 and 5 are effective. The relative velocities of the nodes are the time derivative of the relative displacements in Eq. (13). Using Eq. (18), localized dissipation is active during (potentially unstable) increments of initial separation and subsequent softening. Dissipation is removed once adhesive failure has been well established.

For an iterative static solver with time based incrementation (such as the Newton method solver in Abaqus ${ }^{\circledR} 27$ ), it is necessary for convergence to account for the viscous dissipation in the stiffness matrix. The "viscous stiffness" contribution for a given increment of time $\Delta t$ is given by:

$$
\begin{aligned}
K_{14 i}^{\mu} & =\frac{\mu_{14 i}}{\Delta t}, \\
K_{23 i}^{\mu} & =\frac{\mu_{23 i}}{\Delta t} .
\end{aligned}
$$

\section{The Process Zone}

With Eq. (20), all components of the element stiffness matrix and load vector are complete. The DCZM element derived in the preceding paragraphs has been implemented as a user element in the general purpose non-linear solver Abaqus ${ }^{\circledR}$. Typical load-displacement results after inverse modeling are plotted in figure 6.1, and a typical process zone associated with crack propagation is shown in figure 8 .

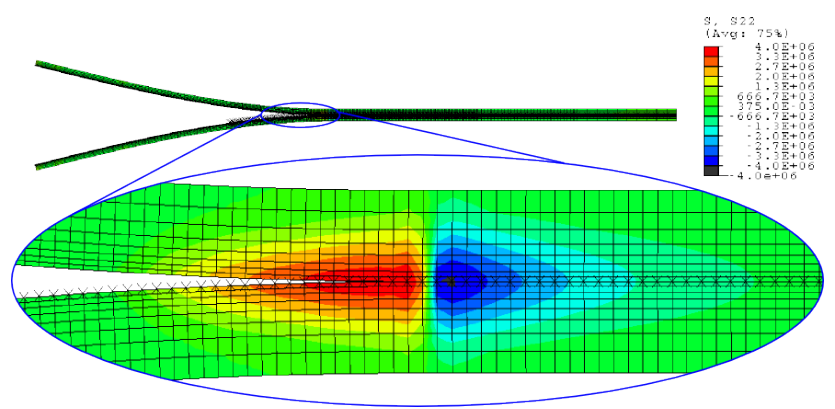

Figure 8: Typical process zone stress field using the current DCZM element.

\section{The Inverse Modeling Procedure}

Returning to the experimental results and using the DCZM element derived above, a second value of the critical energy release rate, $G_{\mathrm{Ic}}^{\mathrm{i}}$, can be established by inverse modeling the measured load-displacement curves in a FE environment. An iterative algorithm has been developed, using custom scripts developed for the numerical package Octave. ${ }^{40}$ Within Octave, the scripts manage the process of supplying initial material properties to the FE model, calling the FE solver, extracting the load-displacement output, evaluating it against the specified convergence criteria, and modifying the input deck for re-analysis if needed.

\section{Metrics for Evaluating the Model Results}

Any inverse modeling technique requires metrics to evaluate model output. The major objective in inverse modeling is to match the experimentally measured loads while accurately representing the geometry and 
material properties, often in the face of uncertainties and experimental variability. For the DCB test in the present work, the principal uncertainties are the stiffness of the adherends, the initial crack length (due to non-planer cracks and measurement error), and the critical energy release rate (due to manufacturing or material variability and unknown temperature dependence). Since $G_{\text {Ic }}$ is the material property of interest, assumptions have to be made regarding the remaining uncertainties.

For the DCB test, two criterion were established as output metrics. The first criterion is to match the initial slope of the load-displacement curve, within a tolerance of $\pm 1 \%$. The initial slope of the loaddisplacement curve is a function of $a_{0}$ and the stiffness of the adherends. Though either could be modified during inverse modeling, the specimen stiffness was held constant and the initial crack position was modified to match the initial load-displacement slope. In matching the initial stiffness by adjusting $a_{0}$, initial crack position is determined within the error bounds of the specimen stiffness.

A second requirement in matching the experimentally determined loads is to predict the load curve during crack advance. Once the stiffness and initial crack length are established, this portion of the load curve is primarily a function of crack advance and also a function of adherend plastic deformation. Since the crack position is the dominant variable and is controlled by $G_{\text {Ic }}$, the DCZM critical energy release rate is used to match the load-displacement curve during crack advance. Plasticity is assumed to be negligible, although the effects of plasticity cannot be completely discounted, particularly at $350{ }^{\circ} \mathrm{C}$.

Prediction of the loads during crack advance is a more nebulous objective than meeting the initial slope of the load-displacement curve, since the measured loads during crack advance are significantly more variable than is the initial slope. A decision must be made with respect to where and how the loads should be evaluated. Common evaluation points are the onset of non-linearity, the $5 \%$ offset point, and the peak load point. ${ }^{37}$ Unfortunately, when evaluated at an isolated point, the calculated value of $G_{\text {Ic }}$ is not an average value, and may not be the best quantitative evaluation of material adhesion. Therefore, in this inverse modeling exercise, an attempt is made to determine the average value of critical energy release rate over the entire crack advance, based on a curve fit of the load-displacement curve during crack advance.

The following procedure was established for determining the critical energy release rate. First, crack advance portions of the curves were isolated from the remainder of the measured and modeled load-displacement curves. The isolated portion of the curve ranged from the displacement at the peak load to the maximum displacement for the specimen (not including overlapping displacements due to cyclic loading). A linear, least-squares fit was applied to each of the isolated curves. Finally, a load value was calculated based on each of the fit lines, where the evaluation point was $1 / 2$ the distance from the peak load to the max displacement of the measured load-displacement curve. These "representative loads" allowed comparison of the measured and modeled crack propagation curves, via the best fit equations. Therefore, the second criterion for the inverse modeling algorithm was that the representative load from the model was within $1 \%$ of the representative load from the measured data.

In the current inverse modeling scheme, there is no procedure in place for evaluating the cohesive strength of the T650/AFR-PE-4/FM680-1 material system, although it could be added without significant difficulty. In the models used in this study, it was determined that the cohesive strength $\left(\sigma_{c}\right)$ and the plastic portion traction separation law govern the transition between the initial slope and the subsequent crack propagation portions of the load-displacement curve. However, other forms of testing are likely to provide a more precise method of determining the cohesive strength. Therefore, effective values of these parameters were chosen (and subsequently not varied), based on the observed transition between initial load-displacement stiffness and crack propagation.

\section{Model Results and Typical FE Output}

Typical FE predictions of the DCB specimen load-displacement using the computed value of $G_{\mathrm{Ic}}^{\mathrm{i}}$ are shown in figure 9, as well as the associated experimental result for the same specimen. The measured load-displacement cycles are well predicted by this method at all temperatures, therefore the values used to create these curves, summarized in table 2 , are very likely to represent the true values present in the material.

Figure 10 shows the distribution of $\bar{G}_{\mathrm{Ic}}^{\mathrm{i}}$ determined by inverse modeling. The values of $\bar{G}_{\mathrm{Ic}}^{\mathrm{a}}$ are found to be larger and more variable than the values of $\bar{G}_{\mathrm{Ic}}^{\mathrm{i}}$. This is expected, since $\bar{G}_{\mathrm{Ic}}^{\mathrm{a}}$ contains energy that is associated with plasticity and other dissipative terms in the experiment, whereas the models used to determine $\bar{G}_{\mathrm{Ic}}^{\mathrm{i}}$ are linear elastic and contain only enough dissipation to ensure a converged static solution. The $\bar{G}_{\mathrm{Ic}}^{\mathrm{i}}$ values are more representative of "true" $\bar{G}_{\text {Ic }}$, since they do not contain significant energy contributions not associated 


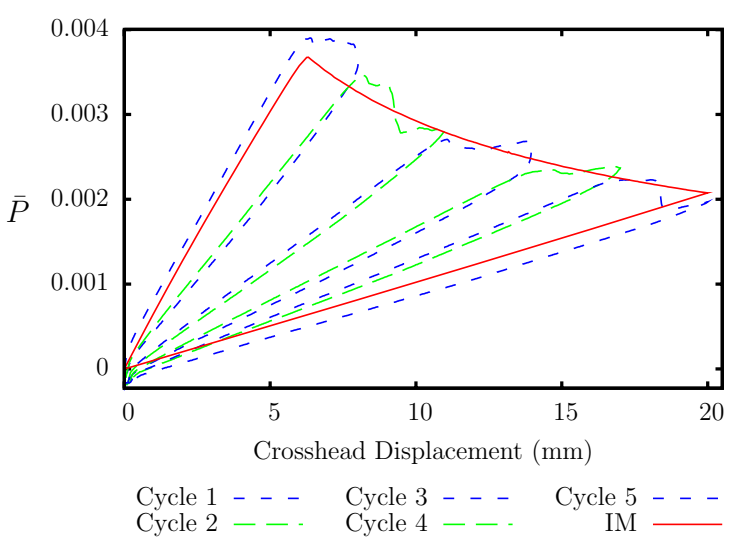

9.1: $T=20^{\circ} \mathrm{C}$

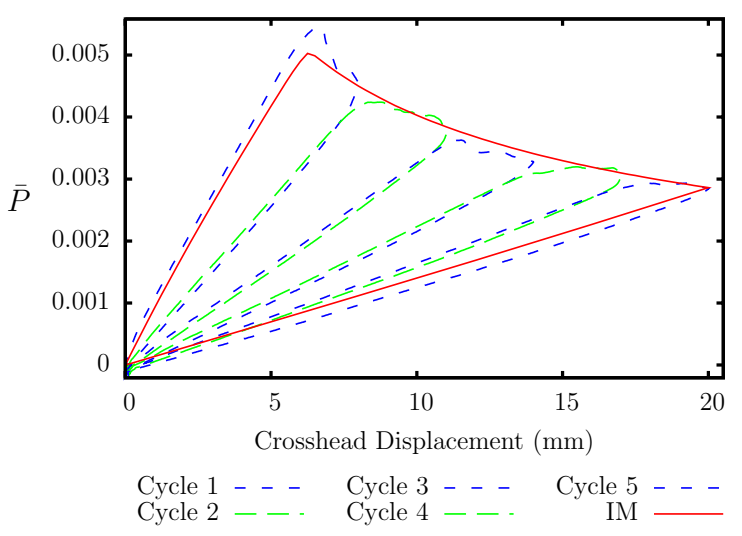

9.3: $T=250{ }^{\circ} \mathrm{C}$

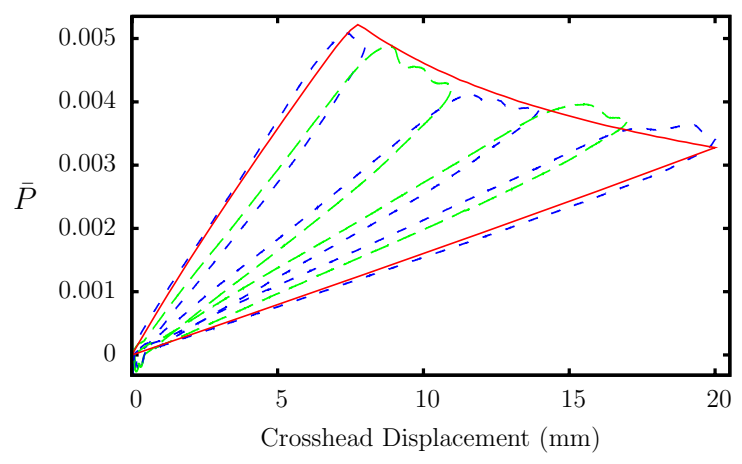

\begin{tabular}{llr} 
Cycle $1--$ & Cycle $3---$ & Cycle $5-\cdots$ \\
Cycle $2-\cdots$ & Cycle $4-\cdots$ & IM - \\
\hline
\end{tabular}

9.2: $T=150{ }^{\circ} \mathrm{C}$

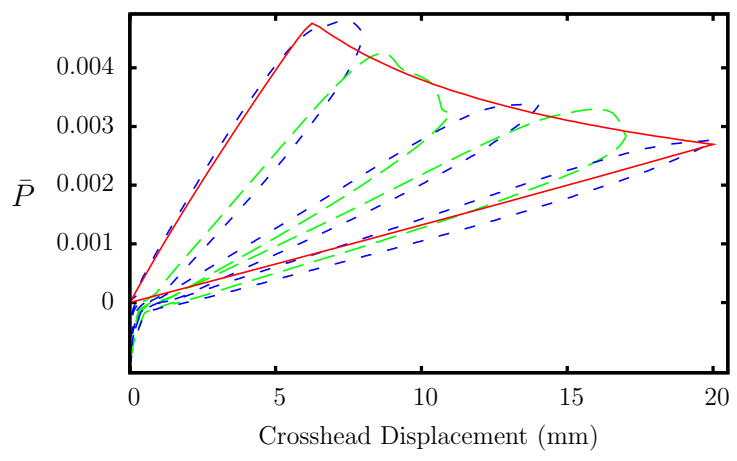

Cycle 1 - - - $\quad$ Cycle 3 - - - Cycle 5 - - Cycle $2-\cdots$ Cycle $4-\cdots \quad$ IM

9.4: $T=350{ }^{\circ} \mathrm{C}$

Figure 9: Typical inverse model comparison with experimental results.

Table 2: Distribution of the computed values of the normalized critical energy release rate

\begin{tabular}{|c|c|c|}
\hline \hline $\begin{array}{c}\text { Temperature } \\
T{ }^{\circ} \mathrm{C}\end{array}$ & $\begin{array}{c}\text { Area Method } \\
\bar{G}_{\mathrm{IC}}^{\mathrm{a}} \pm \sigma\end{array}$ & $\begin{array}{c}\text { Inverse Method } \\
\bar{G}_{\mathrm{Ic}}^{\mathrm{i}} \pm \sigma\end{array}$ \\
\hline 20 & $1.27 \pm 0.36$ & $1.00 \pm 0.21$ \\
150 & $1.38 \pm 0.25$ & $1.23 \pm 0.21$ \\
250 & $1.52 \pm 0.21$ & $1.37 \pm 0.07$ \\
350 & $2.01 \pm 0.79$ & $1.36 \pm 0.22$ \\
\hline \hline
\end{tabular}


with the creation of new crack surfaces. However, the computed values of $\bar{G}_{\mathrm{Ic}}^{\mathrm{i}}$ are not "true" $\bar{G}_{\mathrm{Ic}}$, since the FE models did not include adherend plasticity that may be present.

Comparing the measured and modeled load-displacement curves in figure 9, it is apparent that the DCB test can be well modeled without the inclusion of adherend plasticity. Considering the excellent correlation between modeled and measured load-displacement curves, it is deemed likely that plasticity $\left(W_{\mathrm{pl}}\right)$ is a small portion of the total work, even at $350{ }^{\circ} \mathrm{C}$. It is therefore likely that the other dissipative mechanisms $\left(W_{\text {dis }}\right)$ make up the bulk of the difference between $\bar{G}_{\mathrm{Ic}}^{\mathrm{a}}$ and $\bar{G}_{\mathrm{Ic}}^{\mathrm{i}}$ in table 2 .

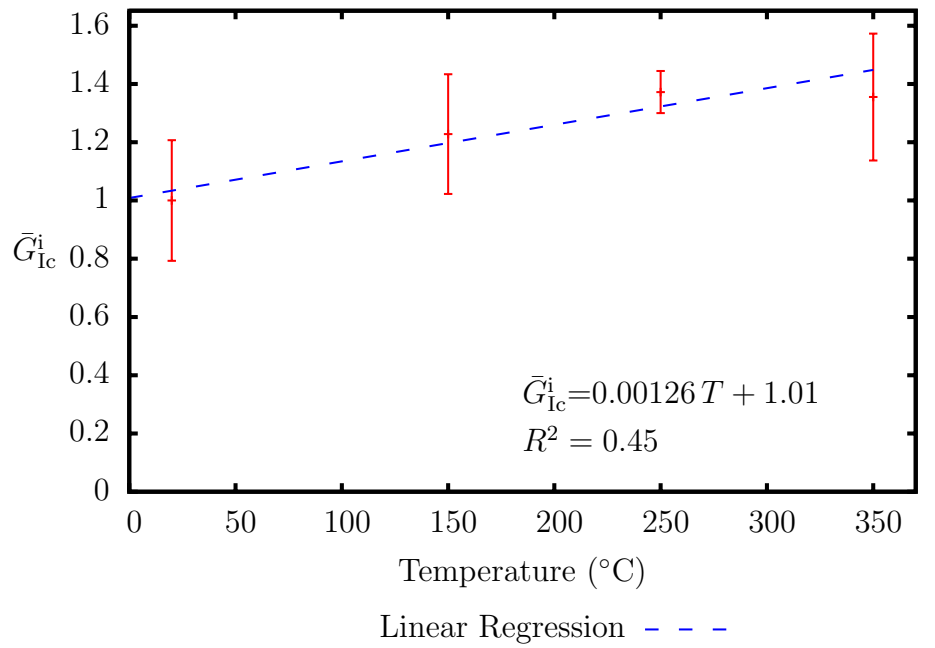

Figure 10: Inverse method critical energy release rate $G_{\mathrm{Ic}}^{\mathrm{i}}$ as a function of temperature. The error bars represent the average $\pm \sigma$ from the local mean.

\section{Conclusion}

An experimental study of the Mode I adhesive properties of a T650/AFR-PE-4/FM680-1 material system has been presented. Two forms of the critical energy release rate were reported based on the area method $\left(G_{\text {Ic }}^{\mathrm{a}}\right)$ and the inverse method $\left(G_{\mathrm{Ic}}^{\mathrm{i}}\right)$. The values of $G_{\text {Ic }}$ were determined as a function of temperature from 20 to $350{ }^{\circ} \mathrm{C}$, and were found to increase with increasing temperature. At $350{ }^{\circ} \mathrm{C}$, the calculation of $G_{\mathrm{Ic}}^{\mathrm{a}}$ was affected by adherend plasticity and failure, as well as other dissipative mechanisms. However, the values of $G_{\mathrm{Ic}}^{\mathrm{i}}$ are not nearly as sensitive to dissipative effects, and produce models with excellent experimental correlation.

Finite element analysis was used, coupled with a novel Discrete Cohesive Zone Model element, to inverse model the experimental results. The DCZM element provides additional function over it predecessor, including a more flexible trapezoidal traction separation law, a standard four-node element layout, and the additional of optional internal damping for improved solution convergence. The traction separation law and the mesh density were found to effect FE solution convergence.

Two metrics were established by which to compare the experimental results with the inverse model output. At the conclusion of the exercise, the inverse model results were found to be in excellent agreement with the experimental measurements. Therefore, the resulting constitutive models provide a range of material properties by which to design and analyze the Mode I behavior of joints made from the T650/AFR-PE4/FM680-1 material system.

\section{Acknowledgments}

This work was supported by the Space Vehicle Technology Institute under grant NCC3-989 jointly funded by NASA and the Department of Defense. It is managed within the NASA Constellation University Institutes Project, with Claudia Meyer as the project manager. Thank you to Cytec Corp. for supplying the pre-preg 
T650/AFR-PE4 cloth, Goodrich Corp. for supplying the FM680-1 adhesive, and Airtech Products for supplying the Kapton Film. At the University of Michigan, thanks are due to Mr. Christopher Churchill for assistance in obtaining the experimental data, and Dr. John Shaw for the use of his thermal test facilities. P.A. Gustafson also extends gratitude to all contributors to the Octave project, which was used for data reduction.

\section{References}

${ }^{1}$ Whitley, K. S. and Collins, T. J., "Mechanical properties of T650-35/AFR-PE-4 at elevated temperatures for lightweight aeroshell designs," Proceedings of the AIAA/ASME/ASCE/AHS/ASC 47th Structures, Structural Dynamics, and Materials Conference, May 1-4 2006, Newport RI, No. 2006-2202, American Institute of Aeronautics and Astronautics, 2006.

${ }^{2}$ Wooley, G. R. and Carver, D. R., "Stress Concentration Factors for Bonded Lap Joints," J. Aircraft, Vol. 8, 1971, pp. $817-820$.

${ }^{3}$ Adams, R. D. and Peppiatt, N. A., "Stress Analysis of Adhesive-Bonded Lap Joints," J. Strain Analysis, Vol. 9, No. 3, 1974, pp. $185-196$.

${ }^{4}$ Kafkalidis, M. S. and Thouless, M. D., "The effects of geometry and material properties on the fracture of single lap-shear joints," International Journal of Solids and Structures, Vol. 39, No. 17, Aug. 2002, pp. 4367-4383.

${ }^{5}$ Xie, D., Waas, A. M., Shahwan, K. W., Schroeder, J. A., and Boeman, R. G., "Fracture criterion for kinking cracks in a tri-material adhesively bonded joint under mixed mode loading," Engineering Fracture Mechanics, Vol. 72, No. 16, Nov. 2005, pp. 2487-2504.

${ }^{6} \mathrm{Li}, \mathrm{S}$., Thouless, M., Waas, A., Schroeder, J., and Zavattieri, P., "Use of a cohesive-zone model to analyze the fracture of a fiber-reinforced polymer-matrix composite," Composites Science and Technology, Vol. 65, No. 3-4, March 2005 , pp. 537-549.

${ }^{7} \mathrm{Li}$, S., Thouless, M., Waas, A., Schroeder, J., and Zavattieri, P., "Competing failure mechanisms in mixed-mode fracture of an adhesively bonded polymer-matrix composite," International Journal of Adhesion and Adhesives, Vol. 26, No. 8, Dec. 2006, pp. 609-616.

${ }^{8}$ Valoroso, N. and Champaney, L., "A damage-mechanics-based approach for modelling decohesion in adhesively bonded assemblies," Engineering Fracture Mechanics, Vol. In Press, Corrected Proof, 2006, pp. -.

${ }^{9}$ Gillespie, Jr, J. W., Carlsson, L. A., and Pipes, R. B., "Finite element analysis of the end notched flexure specimen for measuring mode II fracture toughness," Composites Science and Technology, Vol. 27, No. 3, 1986, pp. 177-197.

${ }^{10}$ Wang, J. T., Raju, I. S., and Sleight, D. W., "Fracture mechanics analyses of composite skin-stiffener debond configurations with shell elements," No. 94-1389-CP, 1994.

${ }^{11}$ Glaessgen, E., Raju, I., and C.C. Poe, J., "Fracture mechanics analysis of stitched stiffener-skin debonding," No. 98-2022, 1998.

${ }^{12}$ Krueger, R., "Virtual crack closure technique: History, approach, and applications," Applied Mechanics Reviews, Vol. 57, No. 2, 2004, pp. 109-143.

${ }^{13}$ Xie, D., Waas, A. M., Shahwan, K. W., Schroeder, J. A., and Boeman, R. G., "Computation of Energy Release Rates for Kinking Cracks based on Virtual Crack Closure Technique," Computer Modeling in Engineering E5 Sciences, Vol. 6, 2004, pp. 515-524.

${ }^{14}$ Xie, D., Salvi, A. G., Waas, A. M., and Caliskan, A., "Discrete cohesive zone model to simulate static fracture in carbon fiber textile composites," 46th AIAA/ASME/ASCE/AHS/ASC Structures, Structrual Dynamics and Materials Conference, 2005.

${ }^{15}$ Xie, D. and Sherrill B. Biggers, J., "Progressive crack growth analysis using interface element based on the virtual crack closure technique," Finite Elem. Anal. Des., Vol. 42, No. 11, 2006, pp. 977-984.

${ }^{16} \mathrm{Munoz}$, J., Galvanetto, U., and Robinson, P., "On the numerical simulation of fatigue driven delamination with interface elements," International Journal of Fatigue, Vol. 28, No. 10, Oct. 2006, pp. 1136-1146.

${ }^{17}$ Goncalves, J. P. M., de Moura, M. F. S. F., and de Castro, P. M. S. T., "A three-dimensional finite element model for stress analysis of adhesive joints," International Journal of Adhesion and Adhesives, Vol. 22, No. 5, 2002, pp. $357-365$.

${ }^{18}$ Goyal, V. K., Johnson, E. R., and Cassino, C., "Computational model for progressive failure of adhesivley bonded joints," 44th AIAA/ASME/ASCE/AHS/ASC Structures, Structrual Dynamics and Materials Conference, 2003.

${ }^{19}$ Davies, G., Hitchings, D., and Ankersen, J., "Predicting delamination and debonding in modern aerospace composite structures," Composites Science and Technology, Vol. 66, No. 6, May 2006, pp. 846-854.

${ }^{20}$ Davidson, B. D., Gharibian, S. J., and Yu, L., "Evaluation of energy release rate-based approaches for predicting delamination growth in laminated composites," International Journal of Fracture, Vol. V105, No. 4, Oct. 2000, pp. 343-365.

${ }^{21}$ Pietruszczak, S. and Mroz, Z., "Finite element analysis of deformation of strain-softening materials," International Journal for Numerical Methods in Engineering, Vol. 17, No. 3, 1981, pp. 327-334.

${ }^{22}$ Ungsuwarungsri, T. and Knauss, W., "The role of damage-softened material behavior in the fracture of composites and adhesives," International Journal of Fracture, Vol. 35, No. 3, 1987, pp. 221-241.

${ }^{23}$ Tvergaard, V. and Hutchinson, J., "The Relation Between Crack Growth Resistance and Fracture Process Parameters in Elastic-Plastic Solids," Journal of the Mechanics and Physics of Solids(UK), Vol. 40, No. 6, 1992, pp. $1377-1397$.

${ }^{24}$ Schellekens, J. and de Borst, R., "On the numerical integration of interface elements," International Journal for Numerical Methods in Engineering, Vol. 36, No. 43-66, 1993, pp. 30-31.

${ }^{25} \mathrm{Xu}, \mathrm{X}$. and Needleman, A., "Numerical simulations of fast crack growth in brittle solids," J. Mech. Phys. Solids, Vol. 42 , No. 9, 1994, pp. 1397-1407.

${ }^{26}$ Camacho, G. and Ortiz, M., "Computational modelling of impact damage in brittle materials," International Journal of Solids and Structures, Vol. 33, No. 20, 1996, pp. 2899-2938. 
${ }^{27}$ ABAQUS, Inc, ABAQUS User Manual v6.5, Electronic Version, 2006.

${ }^{28}$ Camanho, P. P. and Davila, C. G., "Mixed-Mode Decohesion Finite Elements for the Simulation of Delamination in Composite Materials," Tech. Rep. TM-2002-211737, NASA.

${ }^{29}$ Sandia National Laboratory, Tahoe User Guide, 3rd ed., May 2003.

${ }^{30}$ Xie, D. and Waas, A. M., "Discrete cohesive zone model for mixed-mode fracture using finite element analysis," Engineering Fracture Mechanics, Vol. 73, No. 13, Sept. 2006, pp. 1783-1796.

${ }^{31} \mathrm{Cui}, \mathrm{W}$. and Wisnom, M., "A combined stress-based and fracture-mechanics-based model for predicting delamination in composites," Composites, Vol. 24, No. 6, 1993, pp. 467-474.

${ }^{32}$ Shahwan, K. and Waas, A., "Non-self-similar decohesion along a finite interface of unilaterally constrained delaminations," Proceedings: Mathematical, Physical and Engineering Sciences, Vol. 453, No. 1958, 1997, pp. 515-550.

${ }^{33}$ Albouyso, V., Allix, O., Ladeveze, P., and Leveque, D., "Interfacial approach of delamination: possibilities and difficulties," Proceedings of the 12th International Conference on Composite Materials, Paris, France., 1999.

${ }^{34}$ de Borst, R., "Some recent issues in computational failure mechanics," Int. J. Numer. Meth. Engng, Vol. 52, No. 5, 2001, pp. 63-96.

${ }^{35}$ de Borst, R., "Numerical aspects of cohesive-zone models," Engineering Fracture Mechanics, Vol. 70, No. 14, Sept. 2003, pp. $1743-1757$.

${ }^{36}$ Zhou, F. and Molinari, J., "Dynamic crack propagation with cohesive elements: a methodology to address mesh dependency," Int. J. Numer. Meth. Engng, Vol. 59, 2004, pp. 1-24.

${ }^{37}$ Soffa, M. A., Davidson, B. D., and Kumar, M., "Mode I Toughness of a Particulate Interlayered Composite as a Function of Moisture and Temperature," Proceedings of the American Society of Composites $21^{\text {st }}$ Annual Technical Conference, 2006.

${ }^{38} \mathrm{Asp}$, L. E., "The effects of moisture and temperature on the interlaminar delamination toughness of a carbon/epoxy composite," Composites Science and Technology, Vol. 58, No. 6, 1998, pp. 967-977.

${ }^{39}$ Gustafson, P. A. and Waas, A. M., "T650/AFR-PE-4/FM680-1 Mode I Critical Energy Release Rate at High Temperatures: Experiments and Numerical Models," AIAA Journal In Preparations to Be Submmitted, 2007.

${ }^{40}$ Eaton, J., Gnu Octave Manual, Network Theory Ltd., 2002. 